\title{
Inclusive Education and Digital Social innovation
}

\author{
Ileana Hamburg \\ Institut Arbeit und Technik, WH Gelsenkirchen, Munscheidstr. 14, \\ D-45886 Gelsenkirchen, Germany \\ Sascha Bucksch \\ Institut Arbeit und Technik, WH Gelsenkirchen, Munscheidstr. 14, \\ D-45886 Gelsenkirchen, Germany
}

\begin{abstract}
Digital technologies and the internet play an increasingly important role in building innovations with a strong social impact - digital social innovations DSI. Education should support this role and respond at trends as rapid population growth, climate instability, rising poverty, demographic developments. In this paper the role of DSI in inclusive education i.e. in the process of strengthening the capacity of the education systems to reach out to all learners is described. Education for an Inclusive Entrepreneurship i.e. entrepreneurship that contributes to social inclusion to give all people an equal opportunity to start up and operate businesses should be included in strategies of all countries. Particularly target groups in the inclusion process are those who are disadvantage and under-represented in entrepreneurship and self-employment, including youth, women, seniors, ethnic minorities and immigrants, disabled people and many other groups. Examples of projects with authors as active partners and developers of DSI in this context are given.
\end{abstract}

Keywords: Digital technology, Digital social innovations - DSI, Inclusive Entrepreneurship, Inclusive Education, people with disabilities.

\section{INTRODUCTION}

Rapid population growth, climate instability, rising poverty, demographic developments have a present and future impact on lives and work. On the other hand digital technologies and the internet play an increasingly important role in building innovations with a strong social impact. It is very important to find how people are using digital technology in this context. These new social innovations, the digital social innovations (DSI) are not much researched until now i.e. who are the DS innovators, which organizations, and activities support them and which digital tools are used for social change.

It is clear that "Education must be at the core of society's response to these powerful forces. Our collective progress depends on each of us applying knowledge and skills, particularly scientific knowledge and skills, to address these formative and far-reaching issues.I $t$ is critical that we develop a pervasive culture of innovation, not only inside schools, colleges and universities but also within and across communities of students and educators, to drive positive social, economic and technological change“ (Dykes et al, 2013).

Some trends which influence education are:

\section{Economic trends}

Competition in markets, globalization require creative skills and innovativeentrepreneurs which have to be educated. It is recognized that entrepreneurship is a key driver of economy 
and social prosperity.Entrepreneurship is the art of to be able to turn ideas into action. This implies creativity, innovation, risk taking, and the competence to plan and manage projects in order to achieve proposed objectives. The entrepreneurship competence is relevant not only for those who would like to start/carry up a business but for all who would like to support changes in individual, collective, economic and social environments (www.youthpass.eu).

\section{Technological trends}

New methods and media for production and storage of digital Information and development of new forms of communication bring new challenges for learners but also requirements for new skills of teachers and students.

\section{Demographic changes}

Increased aged population, migration, poverty in some countries and decreased birth rate require sustainable lifelong strategies and particularly support for learning in poor countries/regions

\section{Social}

New relationships between individuals require more participation of citizen and changes particularly the education for young people to motivate them to more responsibility and involvement in societal developments. Also complex familiar relationships, increased rate of immigration influence education.

Digital innovations should be used in all sectors of education and training, because technology skills are essential for global citizenship (European Agency, 2014). Such innovations can be particularly efficient for learners with special needs who are vulnerable to the digital divide and to exclusion from some educational opportunities.

In this paper first connections between DSI and inclusive education, particularly in the field of entrepreneurship and in education of people with disabilities are presented. In the next part the using of digital platforms and Apps in inclusive classrooms and examples of projects in this context worked by authors are given.

\section{LITERATURE RESEARCH}

\section{DSI AND EDUCATION}

Innovation has an important role in transforming formal and non-formal education. Education has an important role for preparing students to become entrepreneurs and digital social innovators

Digital technologies can also link the goals and work of innovators. The process of innovation in education should use digital platforms and forums that support open communication and collaboration. Community and networked technologies change how people access information, work and participate physically or digitally in the community.

10 years ago digital technologies in education focused on creating, sharing, and accessing instructional content in digital forms, including online courses, digital libraries, games, and apps. Digitizing educational content, bringing devices to school, and one-off stand-alone learning apps were basic steps in the drive toward bringing technology into classrooms (https://www.linkedin.com/company/future-digital-technologies). 
These technologies can contribute to fortifying student skills, increasing education's ROI, and enabling students to be more innovative and motivate to entrepreneur. To address these challenges, providers of digital technologies will likely need to shift focus from content to connections

"Without a broader vision of social change, new technologies will only serve to reinforce existing institutional goals and forms of social inequity. Many prior attempts to mobilize technology in the service of educational reform have failed because interventions have focused narrowly on the deployment of particular media or technologies, without considering broader social, political, or economic conditions. (Dykes et al, 2013)

"Connected learning is socially embedded, interest-driven, and oriented toward expanding educational, economic, or political opportunity. It is realized when a young person is able to pursue a personal interest or passion with the support of friends and caring adults, and is in turn able to link this learning and interest to academic achievement, career success, or civic engagement. Unlike efforts at educational change that focus on technology deployment or institutional reform, connected learning takes a networked approach to social change that aligns with our ecological perspective." - Mizuko Ito, professor in residence, University of California.

\section{Inclusive education}

Facer (2009) underlines that innovation in technology represents both challenges as well as opportunities for inclusive education. Such digital innovation helps to prepare learners of all ages, particularly with special needs (with disabilities, with immigrant background, from poor families) with the skills that enable them to integrate into education. It is necessary to consider how digital innovations change traditional models of learning and the balance between the development of skills and accumulation of knowledge. By using digital technologies individuals have opportunities to access information and manage their own learning, to communicate with peers and mentors, and to innovate, create and share new materials.

„Inclusive education is a process of strengthening the capacity of the education system to reach out to all learners. As an overall principle, it should guide all education policies and practices, starting from the fact that education is a basic human right and the foundation for European countries at the beginning; qualified teachers and social workers, methodology are missing (European Commission, 2014).

In this context entrepreneurship:

- has been recognized as a major factor for sustainable products and processes

- is a key driver of economy and social prosperity

- has a wide range of meanings i.e. an entrepreneur is a person of very high aptitude who pioneers change, possessing characteristics found in only a very small fraction of the population or anyone who wants to work for own is considered to be an entrepreneur (www.druckersociety.at/repository/scientific/Pearl.pdf), (Hamburg, 2014).

Inclusive Entrepreneurship is entrepreneurship that contributes to social inclusion to give all people an equal opportunity to start up and operate businesses. Particularly target groups in the inclusion process are those who are disadvantage and under-represented in entrepreneurship and self-employment, including youth, women, seniors, ethnic minorities and immigrants, disabled people and many other groups. 
Today nearly 26 million people in the European Union are unemployed and actively seeking work. One of the responses to moving people back into work is through business creation and self-employment, which is a key outcome sought from inclusive entrepreneurship policies, and with it greater labour market participation by the target population groups (European Comission, 2014).

Gary Shaheen from BBI and Mirza Tihic from Syracuse University define inclusive entrepreneurship as:

"A strategy and process for assisting people with diverse disabilities and/or economic and social disadvantages to become entrepreneurs through business planning training, use of customized business development goal and support planning, and access to financial resources utilizing the resources of diverse public and private partners working within a consensusdriven, collaborative framework".

Inclusive entrepreneurship education:

- is in many European countries at the beginning. Digital innovations to support inclusive entrepreneurship education are missing

- is not included in many European countries in the national curricula for vocational education and training (VET) programmes which are very different

- is supported in Germany within the framework curricula for VET set by the Kultusministerkonferenz (Standing Conference of Education Ministers).

It underlines that vocational schools have to provide entrepreneurial ways of thinking and acting and should form part of the corresponding curriculum, but this not the reality in most European countries is tested only in few projects. Future modernisation of VET should systematically include modules of inclusive entrepreneurship.

\section{Inclusive Education For People With Disabilities}

In Germany 80 percent of learners with special needs are in special schools, only about 20 percent attend a regular school. Sure the special educational schools are one way for development of learners with special needs but almost three quarters of all students at special schools do not achieve a secondary school qualification (UNESCO, 2008). Suitable ICT to support inclusive education are missing.

Increasing inclusive education demands require significant changes in all education settings; so mainstream schools have to adapt to diverse groups of students having different needs (O`Gorman 2005; IstenicStarcic, 2009). Learning methods have to be adapted within a diverse population; technologies which support this aspect have to be integrated. Digital innovations play an important role in creating efficient, accessible and adaptable learning environments particularly in inclusive classrooms but most existing hardware and software do not take into consideration different competences/capabilities particularly of people with special needs (Hamburg, .

Providing digital technologies for students with disabilities involves removing barriers i.e. physical barriers, content and materials which are not accessible, cognitive barriers for some learners with intellectual disabilities or specific learning problems, content barriers that may occur when the operating language of a device or software is not the same as a learner's mother tongue, didactical barriers where learning is inflexible and teachers lack of the skills to facilitate inclusive education, financial barriers relating to the costs of devices and software. 
The use of digital technologies in inclusive education requires many sectors of expertise and activities (European Agency, 2014) like stakeholders input and views, training of education professionals and of ICT developers.

Some principles to be taken into consideration in digital technology for inclusive education are:

- an active involvement of learners with disabilities, their families/representatives in the development

- implementation and evaluation of services which facilitates learners access to digital technologies

- the provision of DSI in education of people with disabilities to be aligned with the goals of inclusive education and should be available for formal, informal, blended, social and other forms of learning.

- the implementation of DSI in inclusive education should take a systemic approach.

\section{Apps And Digital Platforms In Inclusive Education And Life}

In inclusive classrooms there are student with different abilities and needs and many teachers are increasingly using an approach in line with the Universal Design for learning framework. Digital developments like apps offer not only classroom distractions, but are also educational and inclusion tools. The challenge is to utilize technology to enhance and transform learning in order to meet the needs of diverse student populations. It is recommended that teachers are using apps that are learner-centred, in which their students can manipulate or create novel content or products of learning. The ability to create content is what will transform student learning-especially for students with special needs (Prupas, 2014; Hamburg and Bucksch, 2015).

Particularly when students are equipped with the right iPad and iPhone apps can enhance their learning process. The teachers or professionals have to develop expertise in facilitating the use of content-creation apps. The teacher's role is the selection and integration of these apps in order for students to be able to explore and control their own learning and life. As there is no prescribed method of using content-creation apps, they can be manipulated and used in many different ways, for many purposes (Prupas, 2014).

Referring parents or professionals working with children/students with disabilities it is important first, to define the difficulties the child/student have. For example, having difficulty with reading, what component of reading is causing him/her to struggle? If the parentscouldcreate own content there are many apps that can be used to create customized learning activities and support thechild/student.

For teachers, parents, professionals it is important to offer apps in two specific categories: support and content creation.

Apps used for curriculum support are those that support a specific area, i.e. literacy, communication, leasure. For a student struggling with decoding, an app that provides text-tospeech could be considered a support in the classroom or for home. Many students, with different learning profiles, can benefit from using text to speech apps as a support in the classroom (Prupas, 2014).

Apps used for content creation are learner-centred; students can create or manipulate their own content with these apps. For example, apps that allow students to enter photos and record their voices on top of the photos can be used to create all kinds of learning products for many 
different purposes; digital stories, social stories, homework journals, or for a personal art project.

The combination of both of these categories of apps in the inclusive classroom or in the home environment creates a wide range of support and creative opportunities for students, with the use of DSI (Prupas, 2014).

\section{RESEARCH APPROACH AND EXAMPLES}

DSI could eliminate the digital divide referring person with intellectual disabilities - IDPs could be i.e. by developing a comprehensive training program for participants in an ICT environment by using suitable apps. The Erasmus + project IdICT - http://www.id-ict.eu/ has as main objective to increase the competences of IDPs, their families and the professionals that work with them for exploiting DSI with a quality of life approach and integrating them in inclusive education.

Specific objectives of the project are:

- to motivate IDPs, their families and professionals, about using ICTs (i.e. apps) for improving their quality of life and helping them to integrate into education

- to develop a training methodology, focused in the transference to accessible and usable guidelines addressed to IDPs, their families and professionals working with them about the appropriated use of ICTs

- to develop an accessible and usable digital training platform, supporting the training methodology linking to selected digital tools i.e. apps.

The digital Training Platform developed by authors is based on Universal Design criteria including awareness, training contents and tailored and adapted training materials for the proper use of the selected ICT solutions based on improving the quality of life of IDP. Trainees and trainers will directly access to the training materials, guidelines and linked selected ICT tools apps and other software. Interactive training sessions will be organised for IDPs, parents, professionals. The next screenshot shows such session(Figure 1).

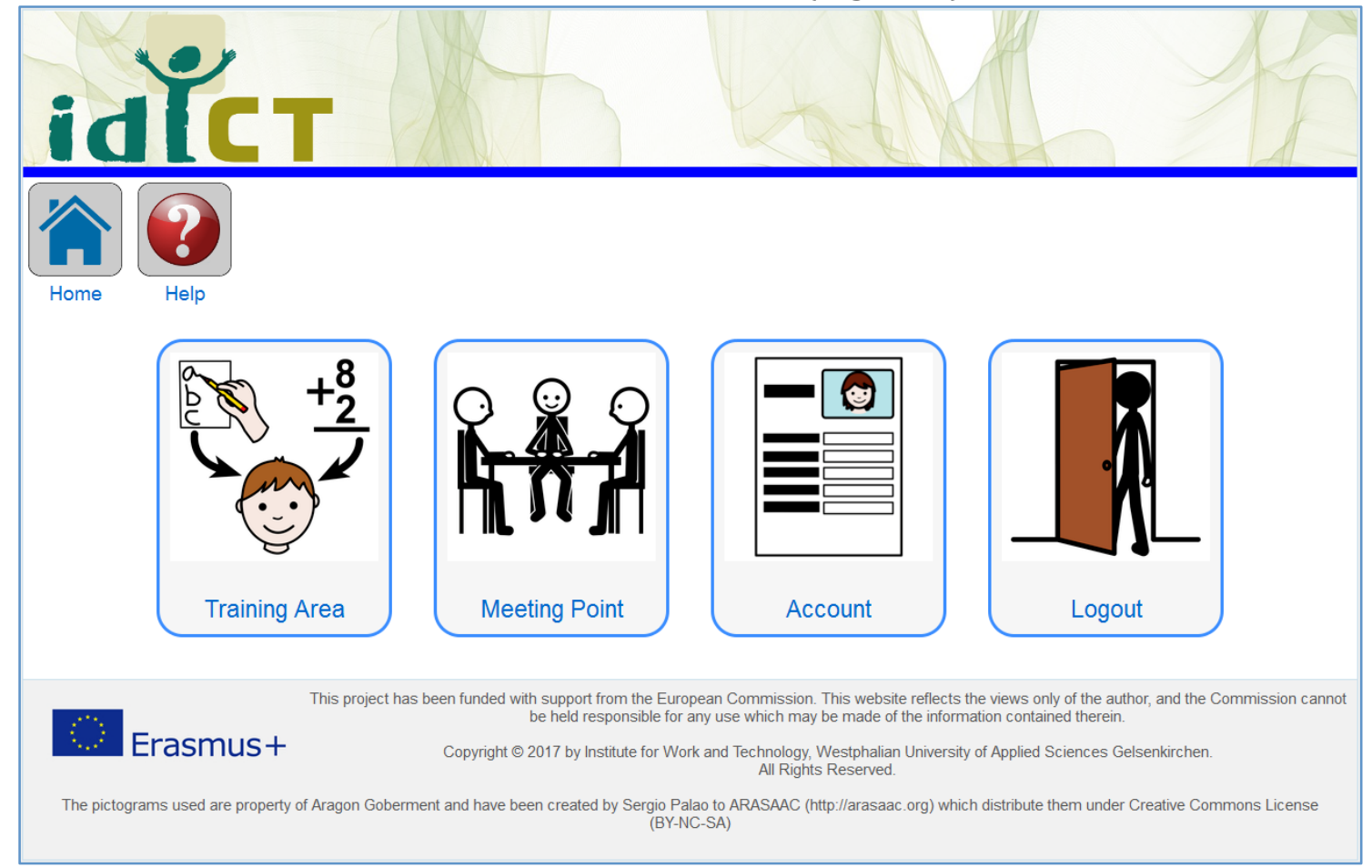

Figure 1: idICTtraining session 
The project consortium includes 5 entities working in the field of supporting persons with Intellectual Disabilities involving a big collective of persons, families and professionals and 2 Technological Centres (specialized in the development of ICT solutions adapted to collectives with special needs and IDPs.

The Erasmus+ project CP-WELLBEING http://www.cpwell.eu/ is launched with the main objective of increasing the competences (attitudes, skills, knowledge) of Persons with Cerebral Palsy - CP- teachers, families and professionals through an innovative training program supported by a digital training platform. Figure 2 shows the project website.

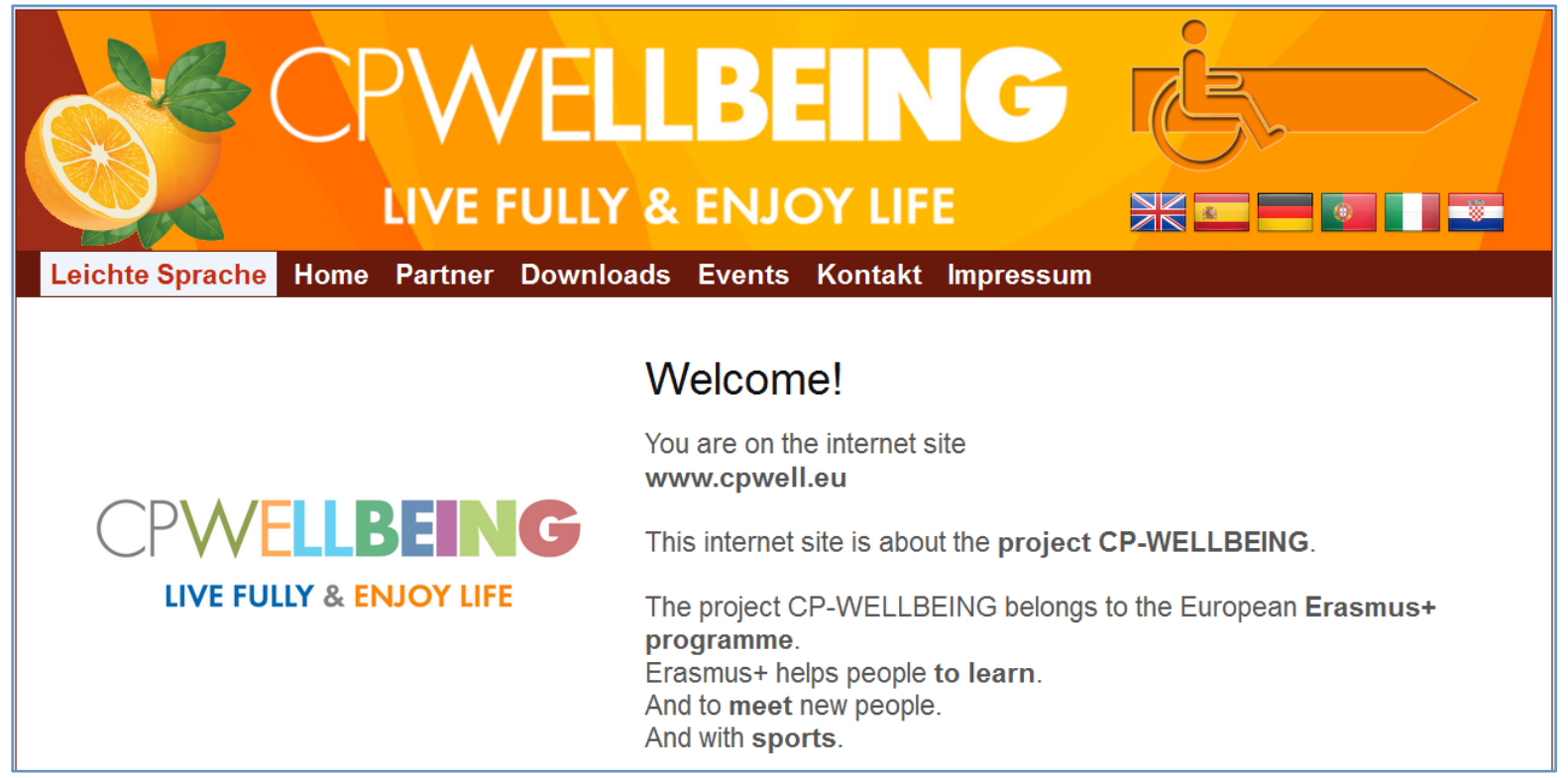

Figure 2: CPWELLBEING Website - http://www.cpwell.eu

The project partners are CP- Organisations, education and research institutions from five European countries.

A guide has been co-created with the direct participation of end users, with the main objective of determining the key contents, methodologies and digital tools to be developed.

Some activities within the project are:

- Development of training materials addressed to persons with $\mathrm{CP}$, teachers, families and professionals to facilitate the implementation of inclusive feeding and integrative and adapted physical activities to be used in experiential training activities.

- Development of an online digital training platform, promoting awareness, training content, tailored and adapted Game solutions to support the training.

- Creation of four training units in all the CP-Associations of the Consortium in order to support the integration of person with CP into education.

\section{CONCLUSIONS}

Information technology is a valuable resources and education could help to create opportunities for each group of citizen to improve their quality of life and to drive social innovation by including them into society and education. There are efforts of governments, of non profitorganisations and private sector but the existing educational systems and teaching methods are not enough adapted to meet rapid evolving nowadays challenges and requirements. Education initiatives should take the problem of inclusion more seriously and 
develop open and extensible learning systems, building cross-cultural networks of DSI innovators and entrepreneurs and fostering cross-disciplinary communities of educators and experts. This is also the objective of future work of authors of this paper and corresponding organisations and projects.

\section{ACKNOWLEDGMENTS}

This paper described work within the on-going European Erasmus+ projects idICT and CPWELLBEING.

\section{References}

Dykes, E., Groff, J., Renfrew-Knight, H., Sutch, D., 2013.Driving social innovation in education. Retrieved from http://www.jengroff.net/pubs_files/Social_Innovation_in_Education 2013

Donelly, V., Watkins, A., 2011.Teacher education for inclusion in Europe. Prospects, 41/3, pp. 341-353.

European Agency, 2014.Model policy for inclusive ICTs in education for persons with disabilities. https://www.european-agency.org/sites/default/files/UNESCO-

G3ict\%20Model\%20Policy\%20on\%20Inclusive\%20ICTs\%20for\%20Education\%204-2014.pdf.

Hamburg, I., Bucksch, S., 2015.ICT-based approaches to support learners with disabilities.In Journal of educational policy and entrepreneurial research (JEPER) 2, no. 6, pp. 1-12.

Hamburg, I., 2014. Improving education and training impact on competitive advantages in SMEs.In International journalof innovative research in electronics and communications (IJIREC) 1, no. 4.

Facer, K., 2009.Educational, Social and Technological Futures: A Report from the Beyond Current Horizons Programme. In Futurelab: Bristol, United Kingdom.

OECD, 2008. Innovating to Learn, Learning to Innovate, National Advisory Committee on Creative and Cultural Education.

David, A.,Hamburg, I., 2013. Integrating vulnerable and marginalized groups into vocational education and training through innovative solutions.In Problems of education in the 21st century, 56, pp. 42-58.

IstenicStarcic, A., 2009. Educational technology syllabus. In UP PEF higher education, pp. 12-15 Koperhttp://jeper.org/index.php/JEPER/article/view/132

O'Gorman, E., 2005. Setting Standards for Teacher Education in Special Educational Needs in Ireland.In 30th Annual Conference ATEE. Amsterdam, October 2005, pp. 377-381

Prupas, A., 2014. Apps for 21st century learning in the inclusive classroom-inclusive classroom podcast https://www.inov8-ed.com/2014/01/apps-for-21st-century-learning-in-the-inclusive-classroom-inclusiveclassroom-podcast/ 